\title{
A Case of Taenia asiatica Infection Diagnosed by Colonoscopy
}

\author{
Heung Up Kim¹, Young-Bae Chung ${ }^{2, *}$ \\ ${ }^{1}$ Department of Internal Medicine and ${ }^{2}$ Department of Parasitology, Jeju National University School of Medicine, Jeju 63241, Korea
}

\begin{abstract}
A case of Taenia asiatica infection detected by small bowel series and colonoscopy is described. The patient was a 42 -year-old Korean man accompanied by discharge of movable proglottids via anus. He used to eat raw pig liver but seldom ate beef. Small bowel series radiologic examinations showed flat tape-like filling defects on the ileum. By colonoscopy, a moving flat tapeworm was observed from the terminal ileum to the ascending colon. The tapeworm was identified as $T$. asiatica by mitochondrial DNA sequencing. The patient was prescribed with a single oral dose $(16 \mathrm{mg} / \mathrm{kg})$ of praziquantel.
\end{abstract}

Key words: Taenia asiatica, tapeworm, colonoscopy, Jeju

\section{INTRODUCTION}

Human taeniases are intestinal infections by the adult tapeworm of Taenia solium, Taenia asiatica, or Taenia saginata. They are caused by eating raw foods of intermediate hosts, such as pigs (T. solium and T. asiatica) and cattle (T. saginata) [1]. Among these parasites, T. asiatica is the latest species found to infect humans, which has morphological characters, such as the existence of a rostellum, posterior protuberance, large number of uterine twigs, and wart-like formation on the larval surface [2]. T. asiatica is distributed in Asian countries, including Korea, China, Japan, Taiwan, Thailand, Vietnam, and the Philippines [3]. In Korea, this tapeworm is the dominant species and widely distributed, including Jeju-do (Province) [4]. The diagnosis of T. asiatica and differential diagnosis from other human Taenia tapeworms have been developed. It is now usually performed by molecular tools using various PCR methods [5]. However, reports of human patients infected with T. asiatica diagnosed by colonoscopy are scarce. In this report, we describe a patient infected with T. asiatica detected by colonoscopy; the species was confirmed by molecular analysis of the worm.

\footnotetext{
- Received 5 December 2016, revised 23 December 2016, accepted 27 December 2016. *Corresponding author (ybchung@jejunu.ac.kr) (c) 2017, Korean Society for Parasitology and Tropical Medicine This is an Open Access article distributed under the terms of the Creative Commons Attribution Non-Commercial License (http://creativecommons.org/licenses/by-nc/4.0) which permits unrestricted non-commercial use, distribution, and reproduction in any medium, provided the original work is properly cited.
}

\section{CASE RECORD}

A 42-year-old man was admitted to a hospital due to daily spontaneous discharge of small pieces of mobile white flat objects. Those were seen during defecation or found on the panty early in the morning. He took several anthelmintics, such as albendazole, over 20 times for a year. However, there was no improvement of the manifestations. He had no other symptoms.

He had been diagnosed with chronic hepatitis B in his childhood. His grandmother advised him to eat raw pig liver regularly to improve the liver function. He also ate raw cattle liver at times. He visited China and South East Asia as a sailor in his third decades. He worked in a home-delivery service and still ate raw pig liver regularly. The vital signs and other physical examination at the initial visit were normal. The laboratory studies, including complete blood count revealed hemoglobin $13.3 \mathrm{~g} / \mathrm{dl}$, white blood cell count $9,100 / \mathrm{mm}^{3}$ (neutrophil $44.1 \%$, lymphocyte $44.6 \%$, monocyte $6.6 \%$, eosinophil $8.3 \%$, basophil $0.4 \%$ ), platelets $196 \times 10^{3} / \mathrm{mm}^{3}$. The blood chemistry test reported total protein $6.9 \mathrm{~g} / \mathrm{dl}$, albumin $6.9 / 4.3 \mathrm{~g} / \mathrm{dl}$, total bilirubin $0.9 \mathrm{mg} / \mathrm{dl}$, aspartate aminotransferase $20 \mathrm{IU} / \mathrm{L}$, alanine aminotranseferase $19 \mathrm{IU} / \mathrm{L}$, alkaline phosphatase $143 \mathrm{IU} /$ $\mathrm{L}$, fasting glucose $82 \mathrm{mg} / \mathrm{dl}$, blood urea nitrogen $14.3 \mathrm{mg} / \mathrm{dl}$, and creatinine $1.1 \mathrm{mg} / \mathrm{dl}$. Serologic tests revealed $\mathrm{HBs} \mathrm{Ag} / \mathrm{Ab}$ $(+/-)$ and $\mathrm{HBe} \mathrm{Ag} / \mathrm{Ab}(-/+)$. The stool examination showed no helminth ova or parasite and negative for occult blood.

To detect the tapeworm, a small bowel series study was performed. The scolex of the tapeworm could not be identified. 

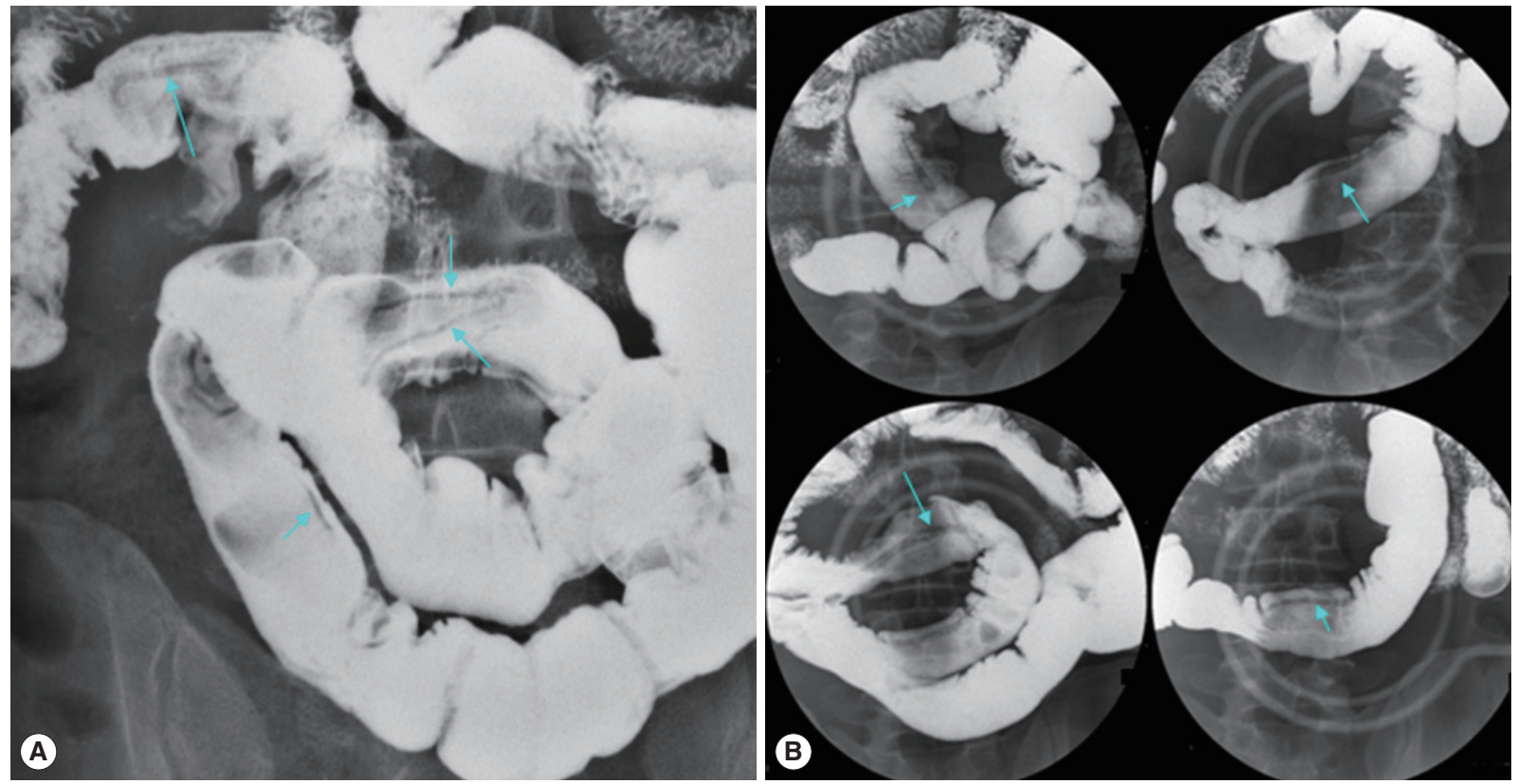

Fig. 1. Small bowel series. The tapeworm (Taenia asiatica) is observed in the ileum (arrows).
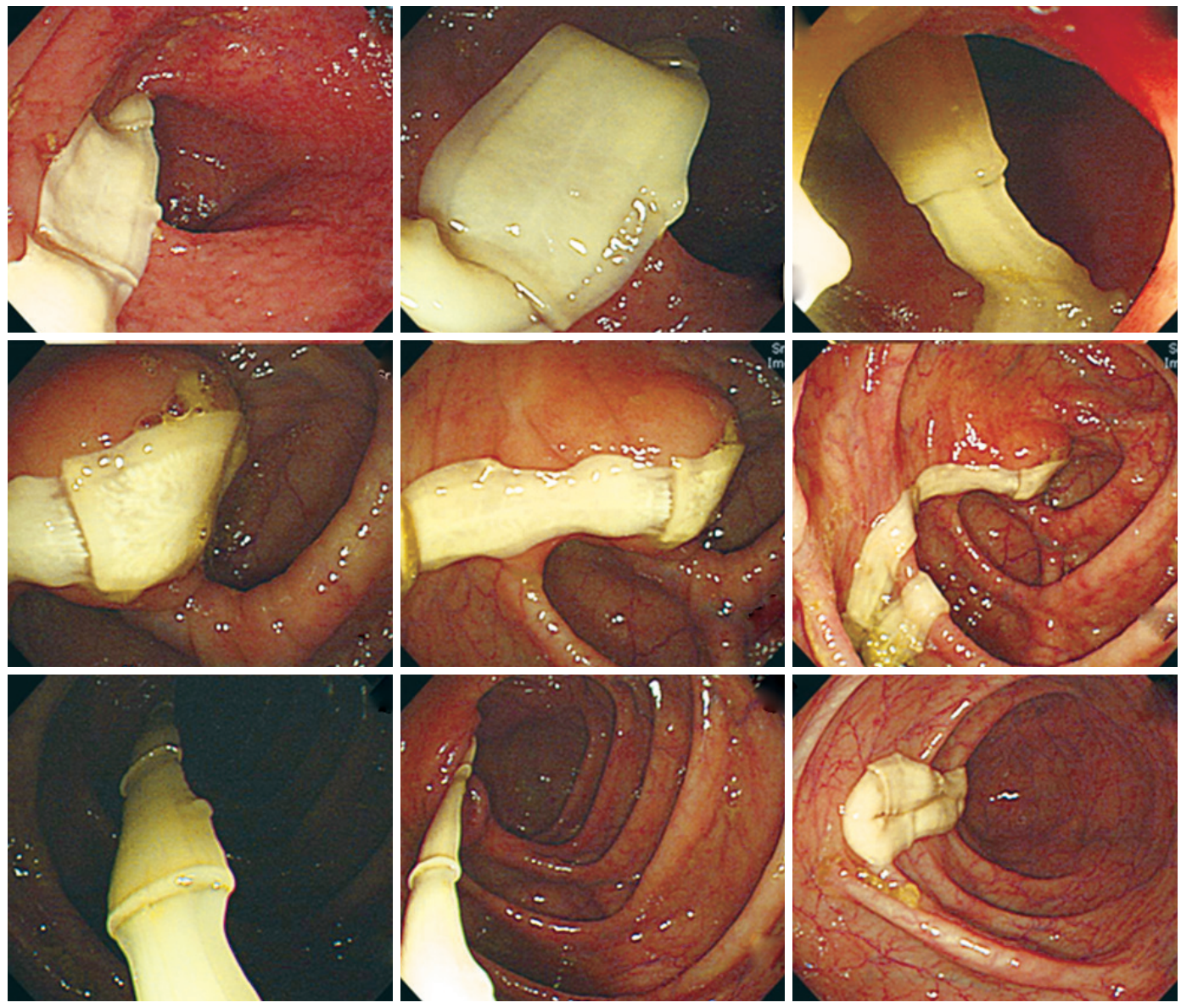

Fig. 2. Colonoscopic features of the terminal ileum and ascending colon. A long bamboo-like tapeworm (Taenia asiatica) is seen. The genital pores and many uterine branches of proglottids are clearly observed. 

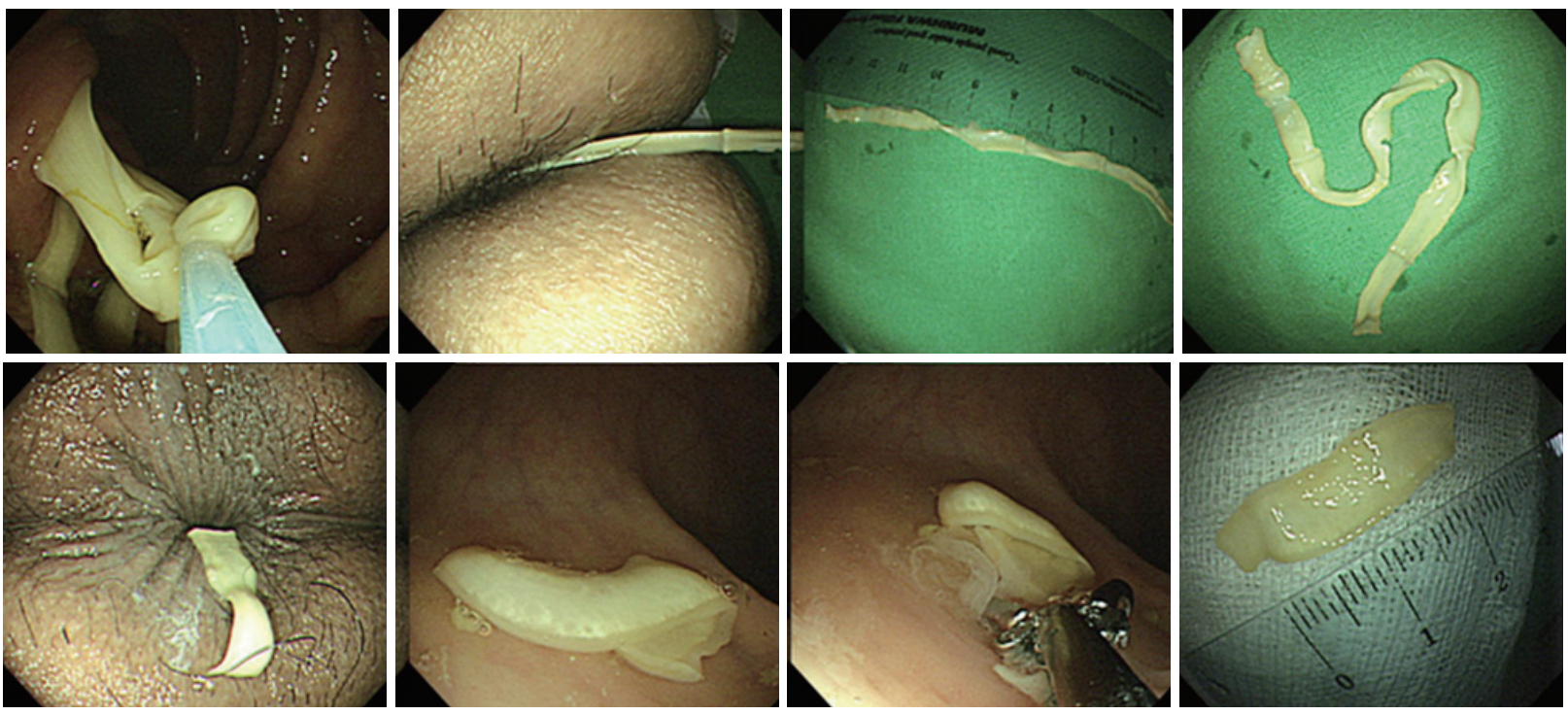

Fig. 3. The tapeworm is removed by a snare and biopsy forceps. The size of proglottids was $2.5 \times 0.6 \mathrm{~cm}$. The removed proglottids had slow contracting motility.

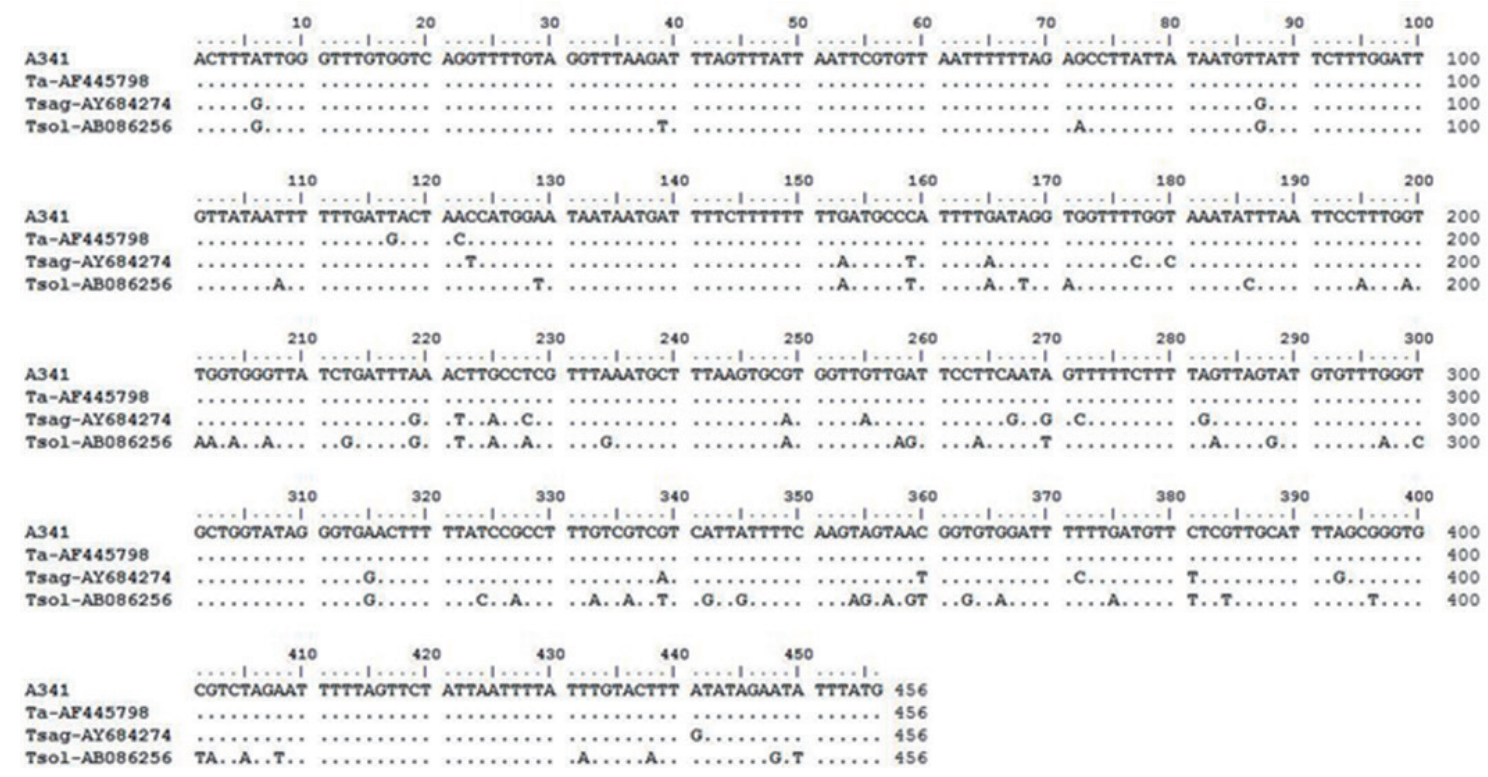

Fig. 4. Sequence alignment of partial mitochondrial cox1 gene of human Taenia tapeworms. Dot (.) indicates identical nucleotide sequence to T. asiatica. Tsol_AB0862256: T. solium, Tsa_AY684274: T. saginata, Ta_AF445798: T. asiatica, A341: Taenia infection in this study.

However, several flat linear tape-like filling defects were seen from the proximal ileum (Fig. 1). Two more linear filling defects were observed in some regions; some were slender and others were thick. It was unknown whether they were overlappings of a single worm or more than 2 worms. To find out proglottids, the whole defecated stool materials were collected in the large film pouch. However, only 3 pieces of proglottids were collected.

Colonoscopic findings showed a milky whitish to slightly yellowish, long flat tapeworm from the ileum to the ascending colon. The proglottids revealed continuous waving motility, and many uterine branches were seen. The genital pore was located at the lateral end of each proglottid (Fig. 2). Uterine branches were well observed when they were passively ad- 
hered on the colonic haustra. At pulling the parasite by endoscopic snare, the proglottids looked like a typical bamboo joint appearance and increased opacity (Fig. 2). After slight pulling of the proglottids, the worm showed active mobility to resist the pulling force and then climbed up to the ileum. Total $12 \mathrm{~cm}$ proglottids were removed; the size of each proglottid was about $2.5 \times 0.6 \mathrm{~cm}$. Several pieces of proglottids remained on the rectum revealed wavy widen-and-narrow motility on horizontal plan (Fig. 3).

Based on these morphological results, the parasite was identified as Taenia sp. The patient was treated with praziquantel $1,200 \mathrm{mg}(16 \mathrm{mg} / \mathrm{kg})$ in a single dose after breakfast. The patient has been in follow-up for 5 years without recurrence. For genetic analysis, the PCR amplification and direct sequencing for the cytochrome $c$ oxidase subunit 1 (cox1) target fragment (456-bp in length corresponding to the positions 67-522 bp of the cox 1 gene) were performed using the total genomic DNA extracted from proglottids of the patient [6]. As a result, the cox 1 sequences of the parasite showed $99 \%$ similarity to the references sequences of the Korean origin T. asiatica (GenBank no. AF445798) (Fig. 4).

\section{DISCUSSION}

It is rare to find a tapeworm by colonoscopy. Although several cases of taeniasis by colonoscopy had been reported [7,8], it did not precisely depict the parasite. The present case showed that colonoscopic findings as well as small bowel series may be useful for diagnosis of intestinal taeniasis.

The patient in this case often ate raw pork and raw pig liver that can cause infection with T. solium. However, the proglottids from this case revealed more than 20 lateral uterine branches, posterior protuberances, and active motility, which are characteristic features for T. asiatica rather than T. solium. In addition, most Taenia tapeworms in Jeju Province collected until 2005 were confirmed to be T. asiatica [4]. From these findings, it was strongly suggested that the tapeworm in this case would be $T$. asiatica even though the patient ate raw cattle liver also. In this study, we could not collect the scolex because it was difficult to recover proglottids at colonoscopy of this patient as well as after administration of praziquantel. The specific diagnosis was possible by genetic analysis of cox1 mitochondrial DNA sequences; the cox1 sequences of our specimen revealed 99\% similarity with the reference sequences of the Korean origin T. asiatica (GenBank no. AF445798) and 95\% similarity with the sequence of T. saginata (no. AY684274). The sequences of T. asiatica and T. saginata showed a 7\% difference, while those of T. saginata and T. solium were differed by $15 \%$ in partial mitochondrial cox1. Taken together our findings, the Taenia species in this case was confirmed as T. asiatica.

The colonoscopy in this study was a useful diagnostic method enough to observe lateral uterine branches and genital pores of the proglottids. If the scolex is located at the distal small bowel, the colonoscopic examinations would be a more powerful tool to find and identify Taenia species. Small bowel series is relatively non-invasive and would be useful to detect the location of strobila. It will be a diagnostic tool of choice in cases of highly suspicious condition for taeniasis because it needs no bowel preparation, minimal invasiveness, and find strobila confined only in the small intestine.

In summary, we diagnosed a case of T. asiatica infection, who had eating habit of raw pig liver, using small bowel series and colonoscopy, and finally identified by mitochondrial DNA sequencing.

\section{ACKNOWLEDGMENTS}

We are grateful to Dr. Hyeong-Kyu Jeon and Prof. Keeseon S. Eom, Department of Parasitology and Medical Research Institute, Chunguk National University School of Medicine, Cheongju, Korea, for their valuable help in genetic analysis. Colonoscopic photos in this case (Fig. 2) had previously been published in a colonoscopic atlas book by Yang SK, Byeon JS, eds, Colonoscopy: Diagnosis \& Treatment. 2nd ed., Seoul, Korea. Kunja Publishing Co. 2009, p 122. We have permission from these authors for using the colonoscopic photo Fig. 2 in this report.

\section{CONFLICT OF INTEREST}

We have no conflict of interest related to this study.

\section{REFERENCES}

1. Eom KS, Rim HJ. Epidemiological understanding of Taenia tapeworm infections with special reference to Taenia asiatica in Korea. Korean J Parasitol 2001; 39: 267-283.

2. Eom KS, Rim HJ. Morphologic descriptions of Taenia asiatica sp. n. Korean J Parasitol 1993; 93: 1-6.

3. Eom KS, Jeon HK, Rim HJ. Geographical distribution of Taenia asiatica and related species. Korean J Parasitol 2009; 47 (suppl): 115-124. 
4. Jeon HK, Kim KH, Chai JY, Yang HJ, Rim HJ, Eom KS. Sympatric distribution of three human Taenia tapeworms collected between 1935 and 2005 in Korea. Korean J Parasitol 2008; 46: 235-241.

5. Jeon HK, Eom KS. Molecular approaches to Taenia asiatica. Korean J Parasitol 2013; 51: 1-8.

6. Jeon HK, Eom KS. Taenia asiatica and Taenia saginata: genetic di- vergence estimated from their mitochondrial genomes. Exp Parasitol 2006; 113: 58-61.

7. Vuylsteke P, Bertrand C, Verhoef GE, Vandenberghe P. Case of megaloblastic anemia caused by intestinal taeniasis. Ann Hematol 2004; 83: 487-488.

8. Petel NM, Tatar EL. Unusual colonoscopy finding: Taenia saginata proglottid. World J Gastroenterol 2007; 13: 5540-5541. 